University of Massachusetts Amherst

ScholarWorks@UMass Amherst

Published Work

Center for Student Success Research

2015

\title{
Researching Students with Disabilities: The Importance of Critical Perspectives
}

Annemarie Vaccaro

University of Rhode Island

Ezekiel Kimball

University of Massachusetts Amherst

Ryan S. Wells

University of Massachusetts Amherst

Benjamin J. Ostiguy-Finneran

University of Massachusetts Amherst

Follow this and additional works at: https://scholarworks.umass.edu/cfssr_publishedwork

Part of the Disability and Equity in Education Commons, and the Higher Education Commons

\section{Recommended Citation}

Vaccaro, Annemarie; Kimball, Ezekiel; Wells, Ryan S.; and Ostiguy-Finneran, Benjamin J., "Researching Students with Disabilities: The Importance of Critical Perspectives" (2015). New Directions for Institutional Research. 5.

https://doi.org/10.1002/ir.20084 


\begin{abstract}
Researching students with disabilities: The importance of critical
perspectives
\end{abstract}

Submitted by:

\begin{abstract}
Annemarie Vaccaro, University of Rhode Island
Ezekiel W. Kimball, University of Massachusetts, Amherst

Ryan S. Wells, University of Massachusetts, Amherst

Benjamin J. Ostiguy, University of Massachusetts, Amherst
\end{abstract}

\footnotetext{
"This is the peer reviewed version of the following article: Vaccaro, A., Kimball, E. W., Wells, R. S., \& Ostiguy, B. J. (2015). Researching students with disabilities: The importance of critical perspectives. New Directions for Institutional Research, 163, 25-41, which has been published in final form at http://doi.org/10.1002/ir.20084. This article may be used for noncommercial purposes in accordance with Wiley Terms and Conditions for Self-Archiving.
} 


\section{Introduction}

Since the passage of the Americans with Disabilities Act (ADA) in 1990, the number of students with disabilities entering postsecondary institutions has increased significantly (United States Government Accountability Office, 2009). Despite the fact that these students comprised roughly 11\% of the post-secondary population in 2007-2008 (National Center for Education Statistics, 2012), higher education research has largely ignored students with disabilities. The small body of empirical research appears most often in small, specialized journals instead of the most prominent higher education publications (Peña, 2014). Critical quantitative scholars are well-positioned to address the need for more research focused on this under-studied population. This chapter describes the complexity of quantitative research examining students with disabilities and outlines what higher education researchers can do to expose and address their marginalization.. The structure of this chapter is inspired by Rios-Aguilar's (2014) framework for conducting critical quantitative work, which builds upon Stage's (2007) conceptualization of critical quantitative research in higher education. A slightly modified version of Rio-Aguilar's list of research activities serves as headings in this chapter. In each section, we describe the challenges of doing critical quantitative research with students with disabilities and offer methodological and theoretical recommendations for navigating these hurdles. We conclude the chapter by explicating how criticalists can inform and challenge higher education policies and practices.

Employ Challenging and Enriching Theories in Multiple Disciplines Exemplary research is thoughtfully grounded in relevant theory (Smart, 2005). This grounding includes both the conceptual framework used to structure an entire research project and more specific theories 
and models that shape research questions, hypotheses, instrumentation, and analyses. Well crafted, critical quantitative research with students with disabilities includes a thoughtful application of critical theoretical perspectives, including critical disability theory. With roots in many critically oriented literatures (e.g., feminist, Marxist, queer, post-colonial, critical cultural studies) critical disability theory covers topics such as: economic, political, physical and social exclusion; oppressive and exclusionary language; and hegemonic ideologies that portray people with disabilities as abnormal, inferior, and unequal (Charlton, 1998, 2006; Davis, 2006; Devlin \& Pothier, 2006). Critical disability studies, like other forms of critical scholarship, emphasizes empowerment, agency and social change.

In addition to utilizing appropriate conceptual frameworks, exemplary researchers also select theories and models relevant to higher education (e.g., engagement, persistence, belonging) that are best suited for the topic of study. Disability studies is multidisciplinary in nature, offering models and theories from a variety of professions and disciplines to help scholars understand complex social realities (c.f. Watson, Roulstone \& Thomas, 2014). Consequently, the most illuminating models and theories for studying college students with disabilities might be found outside higher education (Kezar, 2000; Smart, 2005).

Recommendations: Critical perspectives should shape every aspect of the research process from crafting research questions and hypotheses, through analysis, interpretation, and formulation of recommendations. Exemplary researchers must understand conceptual frameworks well enough to avoid what smart (2005) lamented as a tendency for higher education scholars to use inappropriate, 
incomplete, or superficial applications of theory. Moreover, scholars who study students with disabilities should make use of relevant models and theories from a variety of disciplines such as psychology, sociology, rehabilitation, biomedicine economics, political science and interdisciplinary fields such as disability studies, gender studies, ethnic studies, and cultural studies.

\section{Ask Relevant Questions}

As Stage (2007) noted, critical quantitative research is grounded in the questions that drive the inquiry. A research question can illuminate, or further marginalize, the experiences of students with disabilities. The invisibility of these students in much of the higher education literature suggests most scholars do not consider disability when they conduct studies on topics related to student success. As Davis (2006) argued, studying the experiences of non-dominant populations has become commonplace (i.e., people of color, women), but people with disabilities have "been rendered more invisible than other groups" (p. xv). This is often the case in higher education when researchers compare findings by race, gender, or academic year (e.g., junior, senior), but almost never by ability. Correspondingly, we know little about this population regarding key outcomes of student success. Even studies that focus on students with disabilities can be riddled with problems stemming from non-critically minded research questions. Critical disability scholars have argued that a hegemonic belief in the inferiority of people with disabilities plagues many North American societies (Charlton, 2006; Davis, 2006; Devlin \& Pothier, 2006). It is no wonder that scholarship on students with disabilities is replete with deficit-oriented paradigms. A scan of higher education journal titles about studies including students with disabilities contain phrases such as normal achieving, academically 
struggling, at-risk, accommodations, and services (Peña, 2014). A critical analysis of these research titles might suggest that deficit paradigms prohibit us from seeing students with disabilities as fully equal.

Recommendations: Disability is ubiquitous in higher education. Therefore, disability-informed research questions should be asked of all aspects of campus operations. We recommend institutional researchers and higher education scholars include students with disabilities in critical quantitative studies that span every functional and organizational area of higher education. These students should also be included in research about all important educational outcomes. Finally, we invite scholars to employ a critical disability lens as they generate research questions and hypotheses that include students with disabilities in meaningful and non-deficit ways.

\title{
Choose and/or Collect Relevant Data
}

\author{
When determining what data are relevant to use when studying \\ students with disabilities, researchers should carefully consider the \\ case as the unit from which aggregation occurs and employ methods that \\ minimize limitations of aggregation. That is, researchers should match \\ their dataset to the question they wish to address. Much of the \\ research focuses either on very small (e.g. Dole, 2001; Stage \& Milne, \\ 1996) or very large numbers of students (e.g. Hederson, 2001; Lombardi, \\ Murray, \& Gerdes, 2012). Small quantitative studies could be \\ strengthened through the use of quasi-experimental or experimental \\ designs (e.g. Powers \& Sowers, 1995; Lombardi, Gerdes, \& Murray, 2011$).$ \\ Research focusing on very large number of students is capable of \\ generating information about overall trends but, may yield little \\ information about within group variation (Keller, 1998; Kezar, 2000). \\ These studies could be strengthened by utilizing a more direct
}


theoretical point-of-view (e.g. Abberley, 1987; Hutcheson \& Wolbring, 2012; McClune, 2001). Both small-scale and large-scale research obscure critical aspects of the connection between disability and the postsecondary learning environment. By more carefully considering the purpose of our research and matching unit(s) of analysis to that purpose, more generalizable and actionable research about the experiences of students with disabilities can be produced. Additional points of vulnerability to bias are found in conventional sampling and recruitment procedures that fail to account for communication and response to challenges experienced by students with disabilities (Meyers \& Andersen, 2000). Critical quantitative research into the experiences of this population requires an awareness of how design choices promote or discourage participation of the target population. Poorly conceived sampling plans and modes of recruitment and administration produce biased data by systematically excluding specific subpopulations from research samples (Meyers \& Andersen, 2000; Williams \& Moore, 2011). For example, strict reliance on email for recruiting participants will marginalize non-English speaking Deaf students and present obstacles to those who must limit screen time due to migraine headache triggers. However, shifting to telephone recruitment is not a viable solution since that also presents obstacles to participation (Myers \& Andersen, 2000).

Once sampling concerns have been minimized, or when the researcher is selecting variables from an existing dataset, there are three main sources of potential bias in the resultant dataset: 1) respondents fail to answer the question the researcher intended to ask; 2) researchers fail to ask the question that they wished to have answered; and 3) researchers fail to interpret the results in a way that is contextually meaningful (Bryman, 2012). Since research about 
students with disabilities is particularly prone to each of these data integrity issues, we discuss each in detail.

Respondents fail to answer the question the researcher intended

to ask. A disconnect between the question asked by the researcher and the interpretation of that question by a student taking a survey may result from the nature of disability that has physiological, psychological, and socio-political components. The term disability is a contested and multi-faceted term (Linton, 1998) that carries significant legal implications (Weber, 2001; West, Kregel, Getzel, \& Zhu, 1993). Against an oppressive socio-political backdrop, students undergo a meaning-making process that can result in both individual and contextual identities (Dole, 2001; Jones, 1996; Troiano, 2003) that vary over time (Davis, 2006). As such, designing valid instruments may be particularly problematic since a person may have contradictory identities with regard to disability in each of these two spheres. Research has demonstrated that college students generally have an imperfect ability to report learning and behavior (Porter, 2011, 2013). Questions about the experiences of students with disabilities are also prone to misinterpretation and error in recall. Moreover, critical disability scholars explicate the ways hegemonic messages about inferiority, deficit, and "place in society" can lead people with disabilities to internalize oppression and to adopt "false consciousness and alienation" (Charlton, 2006, p. 224). Critical scholars must be mindful about how such internalization might shape the ways students rate or rank themselves on self-reported measures.

Researchers fail to ask the question that they wished to have answered. Existing research hints that most faculty members have limited understanding of students with disabilities (Humphrey, Woods, \& Huglin, 2011; Salzberg et al, 2002). Critical disability scholars 
argued that this lack of knowledge leads to a "disembodied ivory tower" (Devlin \& Pothier, 2006, p. 9) where researchers without disabilities perpetuate misinformation and discrimination (Davis, 2006). In short, faculty-as-researchers may not accurately capture the experiences of this population, and the same is likely true about institutional researchers.

Furthermore, students with disabilities pose a unique challenge to construct validity. If included at all, research often utilizes disability as a singular construct, but doing so obscures significant differences among students with disabilities. For example, the experiences of students with learning disabilities are distinct from the experiences of students with visual impairments. Determining how to operationalize disability represents a significant professional judgment-a decision that is further complicated by disability's intersectional nature (Davis, 2006; Devlin \& Pothier, 2006). Social identities such as race, class, and gender influence how students will respond to their disabilities and how society responds to them (Davis, 2006; Devlin \& Pothier, 2006; Jones, 1996). Likewise, the levels and types of support available to K-12 students with disabilities are shaped by factors such as parental advocacy, school district resources, and student self-determination (Connor, 2013; Eckes \& Ochoa, 2005; Murray, Lombardi, Bender, \& Gerdes, 2013). The intersections of these socio-political, social class, and human capital resources set the stage for post-secondary experiences. As they design data collection or decide whether or not to utilize a pre-existing instrument, criticalists must acknowledge disability as intersectional and situated in a socio-political context.

\section{Researchers fail to interpret the results in a way that is} contextually meaningful. Without careful attention to the actual 


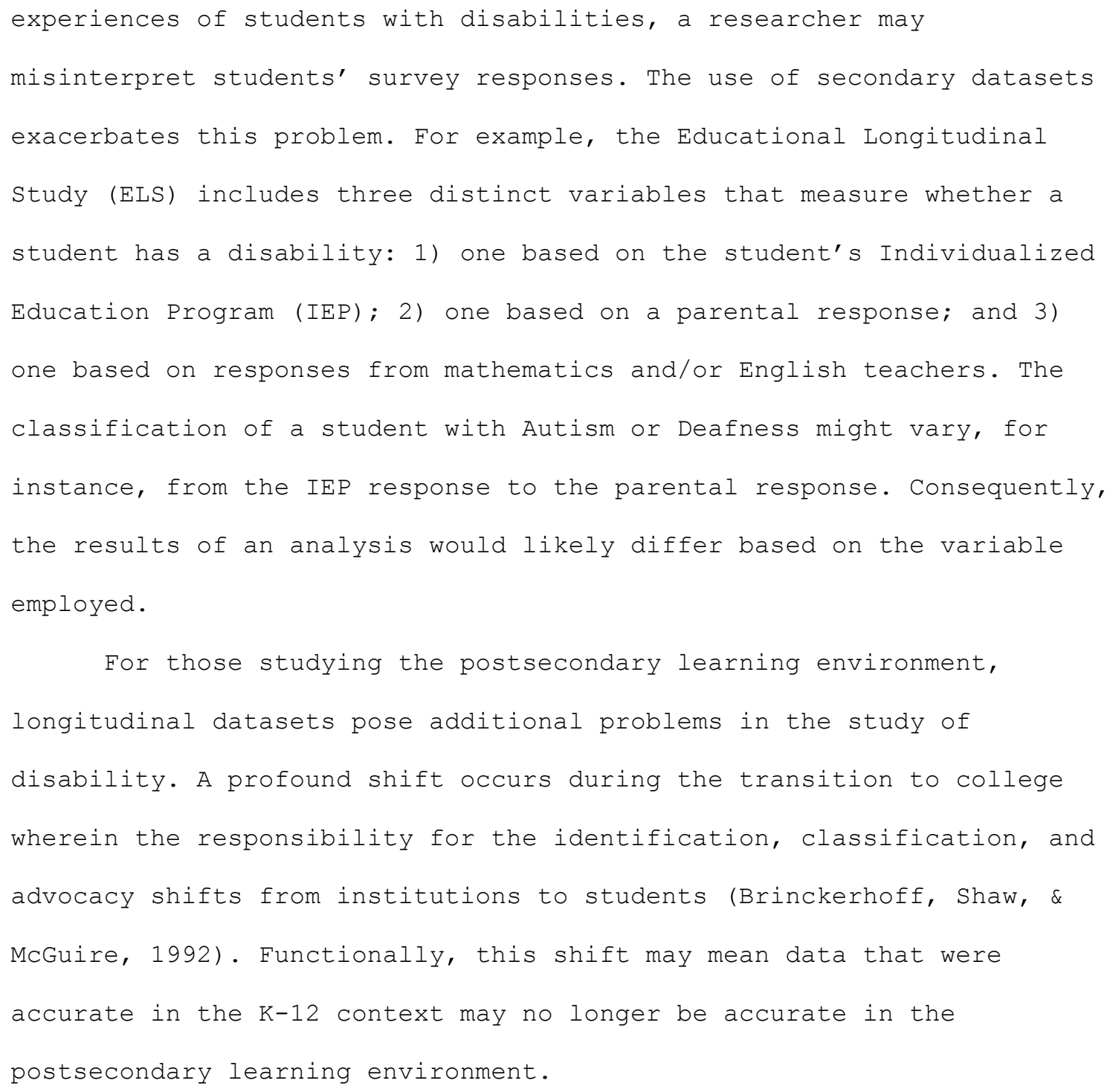

Recommendations. A few research strategies offer promise for assisting researchers in their quest to choose or collect relevant data. First, we believe that researchers should consider universal design principles in study design and implementation.

Universal design means simply designing all products, buildings and exterior spaces to be usable by all people to the greatest extent possible. It is . . a sensible and economical way to reconcile the artistic integrity of a design with human needs in the environment. Solutions which result in no additional cost and no noticeable change in appearance can come about from 
knowledge about people, simple planning and careful selection of conventional products. (Mace, Hardie \& Place, 1009, p. 2)

While early definitions of universal design, like this one, focused heavily on architecture, space, and products, the concept has become increasingly common in education. In the educational literature, universal design typically emphasizes the creation of classroom experiences that are accessible to all (Hackman \& Rauscher, 2004). We contend that universal design can also make research projects more useful, inclusive, and relevant to all.

One way to use these principles is to collect information about disability in studies that do not explicitly focus on disability. Such a step would produce important information about whether more commonly researched areas of higher education differ for students with disabilities. During study design researchers should also consider the accessibility of their sampling plan, data collection method, and dissemination process. Criticalist scholars can oversample very small subpopulations likely to have unique perspectives (e.g., wheelchair users) and employ universal design principles to mitigate barriers to recruitment and response (Williams \& Moore, 2011). Additionally, higher education researchers can look to other fields such as special education, rehabilitation, and counseling for useful approaches.

\section{Apply Appropriate, Rigorous, Sophisticated \& Disaggregated Analyses}

After critical questions are asked and relevant data are collected, researchers must remain critical through data analyses. In general, quantitative research with students with disabilities should be rigorous and adhere to recommended exemplary practices (Smart, 2005). One issue researchers need to consider is the consequences of aggregating students with disabilities for analyses and the implications of such decisions on critical aims of the project. While 
(dis) aggregation of data for other underrepresented groups has been discussed in this volume (Faircloth, Alcantar \& Stage, 2015) and elsewhere (Stage, 2007), it has not been discussed meaningfully for this population. There is a need to critically examine both the impact of aggregating students with disabilities into one category (or even a few) and methods for obtaining more nuanced understandings of this heterogeneous group of students. For example, some quantitative studies simply compare students with and without disabilities, resulting in the homogenization of an extremely heterogeneous population of students. Why is aggregation an issue at all? Quantitative researchers who conduct analyses with data containing small subsamples of students with disabilities often feel the need to aggregate or drop these subsamples, possibly leading to invisibility or mis-representation. With small subsamples, the reliability of estimates produced in the analyses is likely to be low. Thus, researchers may not be able to make strong claims about differences between groups because the value of the estimates may be suspect. In addition, effects may be meaningful, but small samples make reaching the normative thresholds of statistical significance less likely. As such, it may be impossible to know if an effect is actually non-significant or if an effect cannot be detected due to a small sample. Finally, a skewed or unbalanced dataset may be problematic for certain type of analyses, including classifyingoriented work like latent class analysis. An example that highlights the complexity of aggregation comes from research currently in progress (authors Wells \& Kimball) about students with disabilities in STEM majors using the Educational Longitudinal Study (ELS). The aggregation of 2002-2004 ELS data from two sources (parent surveys and IEP records) yields overall and subgroup sizes that differ widely. Table 1 shows subsample sizes for 
students with and without disabilities in data collected from a parent survey while Table 2 was obtained from high school IEP records. As shown, one data source shows 1870 students with disabilities, representing 14.5\% of the population, while the other reveals 1000 students with disabilities, representing about $12 \%$ of the population. Aggregation of data is also problematic when using either source of ELS data individually. In the rows under the raw data in both tables, we present three (problematic) ways to aggregate the data. Aggregating the data in three categories (i.e., learning, physical, other) allows for larger sub-population sizes for analysis, and two categories (i.e., learning and non-learning disabilities) even more so. Aggregating all students with disabilities to compare with students without disabilities gives the simplest groupings for analysis, but is the mos blunt and loses the most information about disability type.

Table 1. Response options and possible aggregations from ELS parental question about disability: "In your opinion, which of these disabilities does your tenth grader have?"

\begin{tabular}{|c|c|c|c|c|c|c|c|c|c|}
\hline 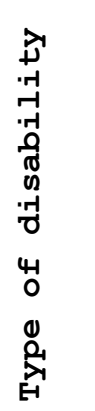 & 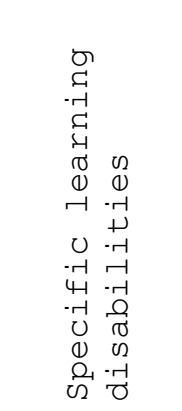 & 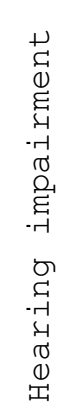 & 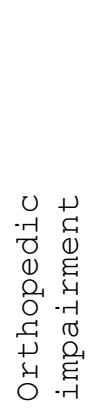 & 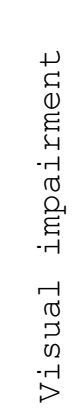 & 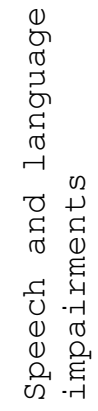 & 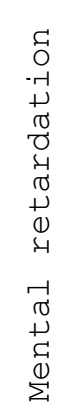 & $\begin{array}{rl} & 0 \\
& 0 \\
& 0 \\
-1 & 0 \\
0 & 0 \\
0 & 0 \\
0 & 0 \\
0 & 0 \\
-1 & 0 \\
+1 & 1 \\
0 & 0 \\
0 & 0 \\
0.7 & -7\end{array}$ & 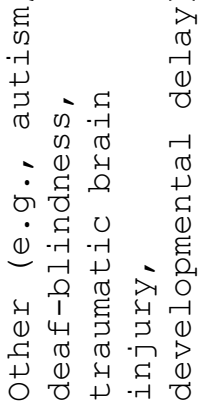 & 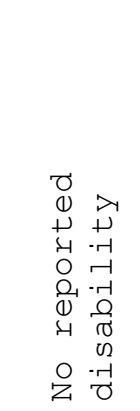 \\
\hline \multirow{4}{*}{ 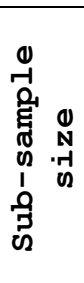 } & 960 & 70 & 50 & 130 & 160 & 30 & 270 & 200 & 11,010 \\
\hline & $\begin{array}{l}\text { Learning } \\
960\end{array}$ & \multicolumn{3}{|c|}{$\begin{array}{l}\text { Physical } \\
240\end{array}$} & \multicolumn{4}{|c|}{$\begin{array}{c}\text { Other } \\
660\end{array}$} & 11,010 \\
\hline & $\begin{array}{l}\text { Learning } \\
960 \\
\end{array}$ & \multicolumn{7}{|c|}{$\begin{array}{c}\text { Other }(\text { non-learning) } \\
910\end{array}$} & 11,010 \\
\hline & \multicolumn{8}{|c|}{ Students } & 11,010 \\
\hline
\end{tabular}

Table 2. Categories and possible aggregations for ELS variable for disability based on data taken from high school IEP records 


\begin{tabular}{|c|c|c|c|c|c|c|c|c|c|c|c|c|c|}
\hline 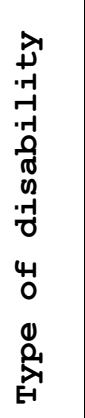 & 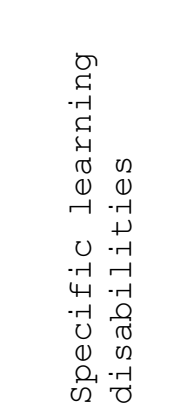 & 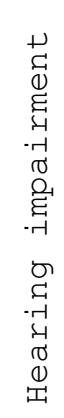 & 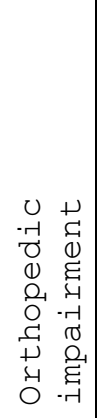 & 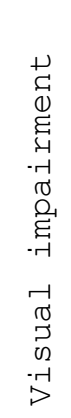 & 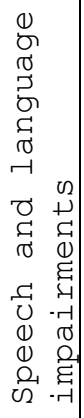 & 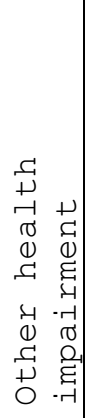 & 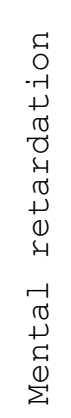 & 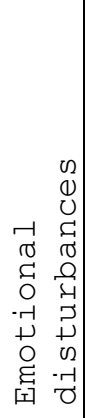 & 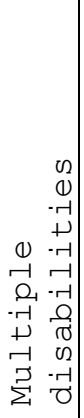 & 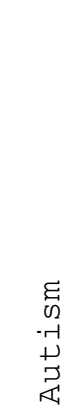 & 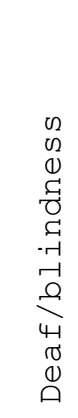 & $\begin{array}{l}\stackrel{H}{1} \\
\stackrel{\lrcorner}{4} \\
\stackrel{+}{0}\end{array}$ & 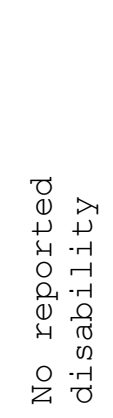 \\
\hline \multirow{4}{*}{ 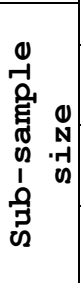 } & 690 & 20 & $<10$ & 20 & 30 & 40 & 90 & 80 & 20 & $<10$ & $<10$ & $<10$ & 7230 \\
\hline & $\begin{array}{l}\text { Learning } \\
690 \\
\end{array}$ & \multicolumn{3}{|c|}{$\begin{array}{l}\text { Physical } \\
40\end{array}$} & \multicolumn{8}{|c|}{$\begin{array}{l}\text { Other } \\
270\end{array}$} & 7230 \\
\hline & $\begin{array}{l}\text { Learning } \\
690\end{array}$ & \multicolumn{11}{|c|}{$\begin{array}{c}\text { Other } \begin{array}{c}\text { (non-learning) } \\
310\end{array}\end{array}$} & 7230 \\
\hline & \multicolumn{12}{|c|}{$\begin{array}{c}\text { Students with disabilities } \\
1000\end{array}$} & 7230 \\
\hline
\end{tabular}

Source: Educational Longitudinal Study (ELS: 2002-04) Notes: Values rounded to the nearest ten in agreement with NCES restricted data license. Errors in addition are due to rounding.

While the statistical norms around, and need for, aggregation are understandable, there are problems with this practice in at least two ways. First, small changes in operationalization of variables (in this case aggregation of disability categories) can lead to interpretations of results that may be quite different, and in danger of being overgeneralized (Wells, Lynch \& Seifert, 2011). In addition, the experiences of very small groups of students (e.g., Autistic or Deaf) will be hidden when they are aggregated with data from students with vastly different disabilities.

Recommendations: Given these challenges with analyses, and particularly with (dis)aggregation, one recommendation is to collect data that oversample students with disabilities, thereby allowing robust analyses of many subgroups. If researchers are at the mercy of previously collected data, they can create groups in a manner that leads to thoughtful and nuanced understandings of students with disabilities. For example, Beginning Postsecondary Students (BPS) data 
have pre-aggregated groupings for type of disability: Mobility, Sensory, and Other. While these classifications may be useful in some research projects, they may be inappropriate in others. Critical researchers should consider the context of their specific study before adopting any pre-defined groupings.

Researchers may find it useful to use a theoretical or conceptual grounding to create groups, rather than using a generic default group. Based on theory or contextual understanding, researchers can make a case for why some groups of students can more appropriately be grouped together, hopefully limiting mis-aggregation and invisibility of particular students with disabilities. For instance, a study that was focused on issues of disclosure, stigma, or self-concept might logically benefit from grouping students with apparent (visible) disabilities and those with non-apparent (invisible) disabilities (e.g., Olney \& Brockelman, 2005) Empirical techniques can also be used to group students in ways the data suggest are appropriate. For instance, cluster analyses can be used to create categories based upon shared experiences (e.g., climate experiences) rather than grouping participants strictly by disability diagnoses (e.g., learning disability, visual impairment). Cluster analyses may also indicate that existing disability categories do not predict useful groupings based on experiences. Other types of personcentered analytic techniques will also be useful in this regard (see Malcom-Piqueux in this volume).

In any type of grouping -- empirical, theoretical, or both -- the outcome being studied must be taken into consideration. For example, in some cases grouping autism with several other types of disabilities as "other disabilities" might make sense, as shown with the ELS data above (despite the problematic labeling practice of explicitly "othering" 


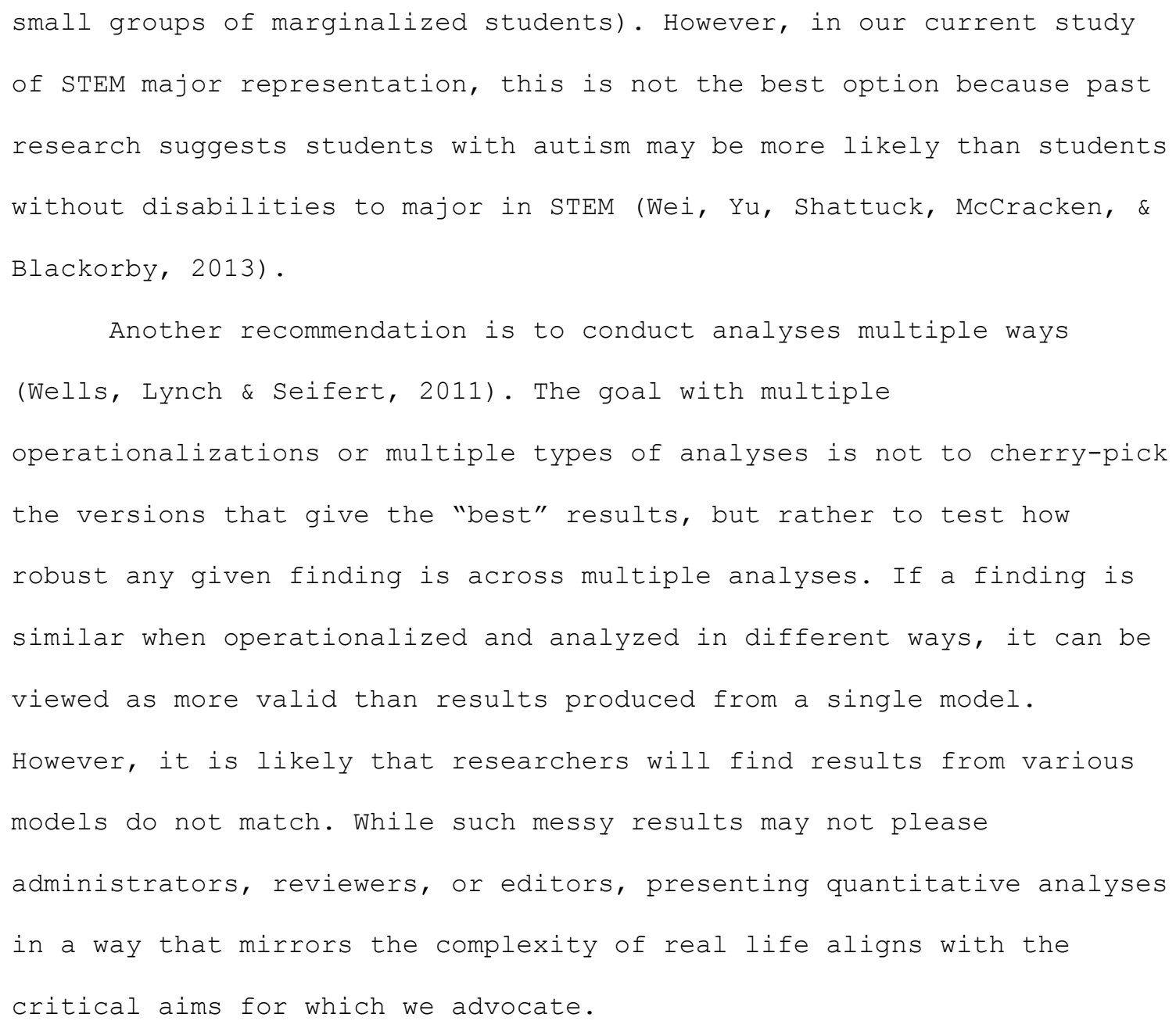

Know How to Interpret Results

A critical interpretation of results can only occur if a study is designed to address critical questions. Beyond that, knowing how to interpret results first and foremost means knowing the methods used. For example, if one uses logistic regression, one must know how to substantively interpret logit coefficients and odds ratios. Considerations of "significance" dominate many researchers" thinking about all quantitative methods. As such, our understandings about students with disabilities are limited to "rigorous" studies that yield statistically significant findings. Smart (2005) suggested the field of higher education has relied too much on statistical significance and not enough on substantive significance. Rios-Aguilar 
(2014) problematizes the notion of significance even further by using the term "educational significance" to remind researchers to consider what results "mean practically for underrepresented and marginalized groups of students' experiences and opportunities" (p. 99).

Recommendations: We recommend that, when appropriate, quantitative criticalists push the boundaries of field and institutional norms around statistical significance when interpreting results. If the educational or substantive significance of a finding for a specific sub-group of students with disabilities is worthy of attention, the finding should be discussed regardless of whether it is statistically significant using common cut-offs such as "at the .05 level." For example, if a large difference were found in the effect of a policy on the retention students with versus those without disabilities, but the finding was not statistically significant, it typically would be omitted from a report or paper. However, a transparent discussion about the possible educational or substantive significance of the finding, preferably through the lens of actual effect sizes, could still be justified from a critical perspective. There is no need to over-claim the importance of such a finding in future research, but being silent about potential real-world significance for a marginalized group based on the rigid, often arbitrary conventions and norms of the quantitative research community (Ziliak \& McCloskey, 2008), does not increase our knowledge of this important population of students. In fact, in future research "less rigorous" yet educationally significant results may be very effective in laying the groundwork for future analyses that meet the more rigorous norms of the quantitative research community. It is precisely these small pushes by critical researchers that cumulatively may have an impact on the state of the field in researching, understanding, and 
supporting students with disabilities.

\section{Inform and Challenge Existing Educational Policies and Practices}

Critical scholarship is never about research for research's sake (Devlin \& Potter, 2006; Giroux, 1997; Kincheloe and McLaren, 2005). Kincheloe and McLaren (2005) argue "inquiry that aspires to the name 'critical' must be connected to an attempt to confront. . . injustice" (p. 305). Devlin and Pothier (2006) describe the goal of critical disability theory as "a politics of transformation" (p. 12). These paradigms align nicely with Rios-Agular's (2014) research activities that critical quantitative scholars must engage in - informing and challenging exclusionary educational policies and practices. Yet, the higher education literature contains a dearth of research about students with disabilities (Peña, 2014), making research-informed policy decisions nearly impossible. A lack of critical inquiry about students with disabilities in all realms of higher education, leads practitioners to create policies and services that do not consider the needs of this growing group of students. Such exclusions have not only ethical, but potentially legal ramifications for higher education institutions.

Recommendations: Critical disability scholars emphasize agency and empowerment of people with disabilities (Charlton, 2006; Davis, 2006; Devlin \& Pothier, 2006). Educational leaders can increase a sense of agency and empowerment in students with disabilities by encouraging the use of universal design in not only teaching, but also research. As Berger and Thanh (2004) suggest, universal design can be facilitated by cultural and organizational factors within an institution. For instance, leaders can offer special recognitions of inclusive research in university marketing materials, research award decisions, and the tenure and promotion processes. Internal and external grant 


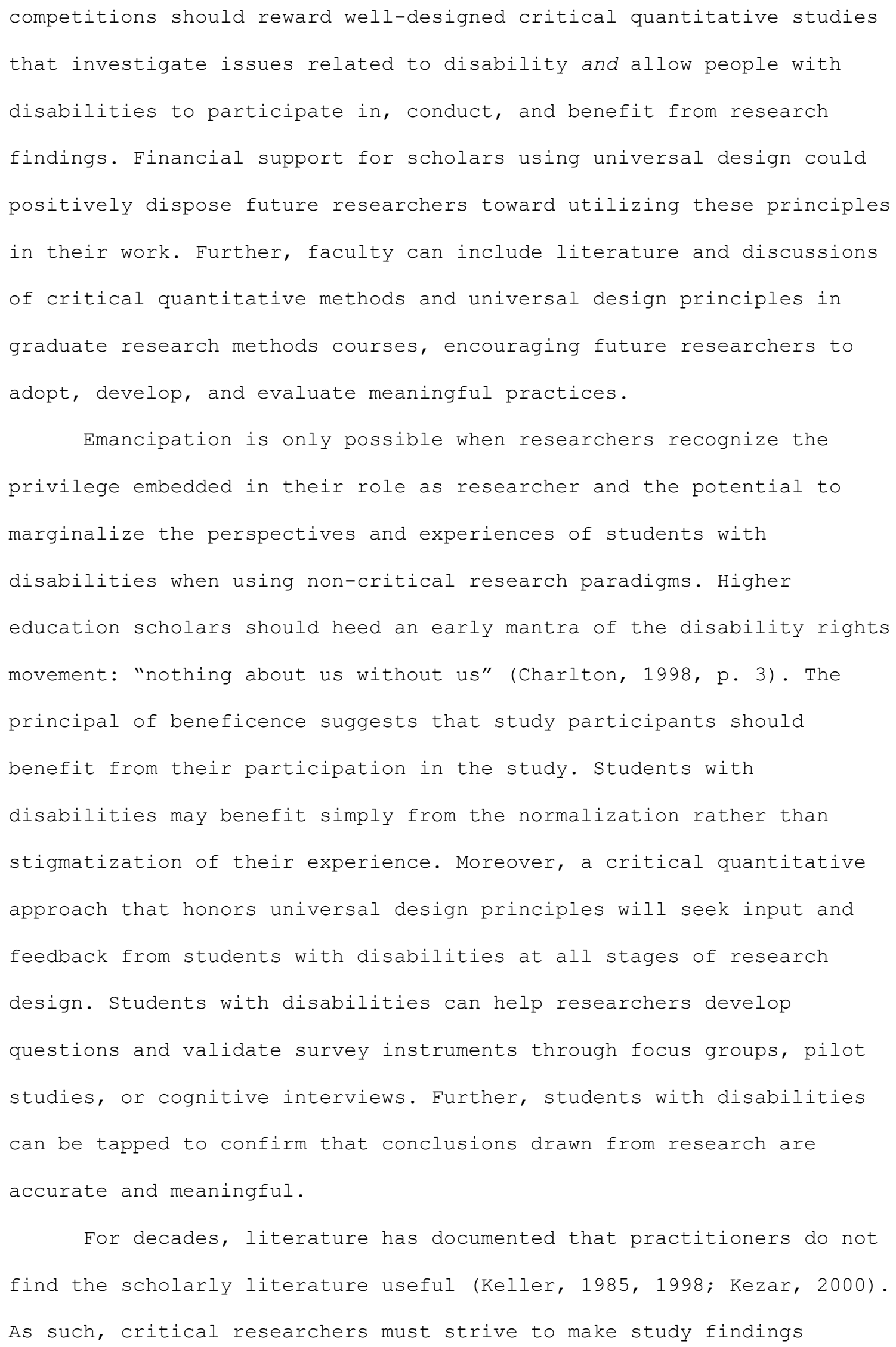


accessible and useful to those who create policy and work directly with students with disabilities. There is a need to close the gap between research and the practices associated with the full inclusion of this population. In this regard, offices of disability services and professional associations (e.g., AHEAD) can be resources to scholars, regardless of research focus, as they begin to formulate their research questions, design their studies, and interpret data. Disability services professionals can offer researchers insight into how to best capture the perspectives of diverse students via accessible research design.

If critical scholarship is intended to inspire action, then it must be accessible to practitioners who directly interact with students and to educational leaders who create policies. In her study of practitioners and researches, Kezar (2000) found practitioners desired research that was timely, offered suggestions for best practices, and described solutions for daily practice dilemmas. Critical researchers should heed these suggestions when writing for both internal and external audiences. For critical scholars to inspire action, they must go beyond merely publishing in scholarly journals and presenting in scholarly conference venues (Keller, 1985). Criticalists must also speak directly to those working with students with disabilities. Key findings along with practice-based recommendations should be submitted to widely-read publications (e.g., professional newsletters, magazines, and volumes such as this one). Finally, and most importantly, research findings should be shared with campus entities, creating a reciprocally beneficial dynamic that "help[s] to shrink the gap between equityminded research and policy" (Stage \& Wells, 2014, p. 3).

\section{Conclusion}


The application of critical quantitative practices to disability research presents a number of transformational opportunities for higher education. A persistent and important theme in the critical disability literature is that disability oppression is the result of socially imposed limitations (Shakespeare, 2006). Understood in this theoretical context, disability in higher education constitutes an important opportunity to capitalize on the strengths of critical quantitative methods by asking compelling questions and giving voice to this significant, yet understudied postsecondary population.

Thoughtfully conducted, critical quantitative research about the experiences of students with disabilities can contribute to the development of institutional policies and practices that liberate rather than exclude. However, critical application of research data can only occur when critical questions are asked and data have been collected and analyzed with a design that allows for critical interpretation. There are a host of methodological challenges in conducting critical research with students with disabilities. While none of our recommendations offer perfect solutions to these tough methodological problems, omitting disability from higher education research or conducting non-critical inquiries with students with disabilities, will only contribute to the oppression of this marginalized population. Instead, by shifting from normative methodological considerations to the transformative potential of critical quantitative work as a guiding principle, scholars can produce research that will illuminate the experiences of an underserved and under-researched population in higher education. 


\section{References}

Abberley, P. (1987). The Concept of Oppression and the Development of a Social Theory of Disability. Disability, Handicap \&amp; Society, $2(1), \quad 5-19$. doi:10.1080/02674648766780021

Berger, J. B., \& Thanh, D. (2004). Leading Organizations for Universal Design. Equity \& Excellence in Education, 37(2), 124-134. doi:10.1080/10665680490453959

Brinckerhoff, L. C., Shaw, S. F., \& McGuire, J. M. (1992). Promoting Access, Accommodations, and independence for college students with Learning Disabilities. Journal of Learning Disabilities, 25(7), $417-429$

Bryman, A. (2012). Social Research Methods (4 edition.). Oxford University Press, USA.

Charlton, J. I. (1998). Nothing about us without us: Disability oppression and empowerment. University of California Press. Charlton, J. I. (2006). The dimensions of disability oppression: An overview. In L. J. Davis (Ed.), The disability studies reader (2nd ed.) (pp. 217-227). New York: Routledge.

Connor, D. J. (2013). Sink or Swim: Managing the Academic Transition to College for Students with Learning Disabilities. Journal of College Student Retention: Research, Theory and Practice, 15(2), 269-292. doi: $10.2190 / \mathrm{CS} \cdot 15.2 .9$

Davis, L. J. (2006). Introduction. In L. J. Davis (Ed.), The disability studies reader (2nd ed.) (pp. xv-xviii). New York: Routledge.

Devlin, R. \& Pothier, D. (2006). Introduction: Toward a critical theory of dis-citizenship. In D. Pothier \& R. Devlin (Eds.) Critical disability theory: Essays in philosophy, politics, policy and law. Vancouver, Canada: UBC Press. 
Dole, S. (2001). Reconciling Contradictions: Identity Formation in Individuals with Giftedness and Learning Disabilities. Journal for the Education of the Gifted, 25(2), 103-37.

Eckes, S. E., \& Ochoa, T. A. (2005). Students with Disabilities: Transitioning from High School to Higher Education. American Secondary Education, 33(3), 6-20.

Hackman, H. W., \& Rauscher, L. (2004). A Pathway to Access for All: Exploring the Connections Between Universal Instructional Design and Social Justice Education. Equity \& Excellence in Education, $37(2), 114-123$. doi:10.1080/10665680490453931

Hutcheon, E. J \& Wolbring, G. (2012). Voices of "disabled" post secondary students: Examining higher education "disability" policy using an ableism lens. Journal of Diversity in Higher Education, $5(1), 39-49$. doi: $10.1037 / a 0027002$

Jones, S. R. (1996). Toward inclusive theory: Disability as social construction. NASPA Journal, 33, 347-354.

Keller, G. (1985). Trees without fruit: The problem with research about higher education. Change, 17 (1), 7-10.

Keller, G. (1998). Does Higher Education Research Need Revisions? The Review of Higher Education, 21(3), 267-278. doi:10.1353/rhe.1998.0005

Kezar, A. J. (2000). Higher Education Research at the Millennium: Still Trees without Fruit? The Review of Higher Education, 23(4), 443468 .

Kincheloe, J. L. \& McLaren, P. (2005). Rethinking critical theory and qualitative research. In N. K. Denzin \& Y. S. Lincoln (Eds.), The Sage Handbook of Qualitative Research (3rd ed.) (pp. 303-342). Thousand Oaks, CA: Sage. 
Linton, S. (1998). Claiming Disability: Knowledge and Identity. New York: NYU Press.

Lombardi, A., Gerdes, H., \& Murray, C. (2011). Validating an Assessment of Individual Actions, Postsecondary, and Social Supports of College Students with Disabilities. Journal of Student Affairs Research and Practice, 48(1), 104-123. doi:10.2202/1949-6605.6214 Lombardi, A. R., Murray, C., \& Gerdes, H. (2012). Academic Performance of First-Generation College Students with Disabilities. Journal of College Student Development, 53(6), 811-826. doi:10.1353/csd.2012.0082

Mace, R. L., Hardie, G. J., \& Place, J. P. (1990). Accessible Environments: Toward Universal Design. Center for Accessible Housing, North Carolina State University. Retrieved from: http://www.ncsu.edu/www/ncsu/design/sod5/cud/pubs_p/docs/ACC\%20Envi ronments.pdf

McClune, B. (2001). Modular A-levels - who are the winners and the losers? A comparison of lower-sixth and upper-sixth students' performance in linear and modular A level physics. Educational Research, 43(1), 79-89. doi:10.1080/00131880010021302 Murray, C., Lombardi, A., Bender, F., \& Gerdes, H. (2013). Social support: main and moderating effects on the relation between financial stress and adjustment among college students with disabilities. Social Psychology of Education, 16(2), 277-295. doi: $10.1007 /$ s11218-012-9204-4

Meyers, A. R., \& Andresen, E. M. (2000). Enabling our instruments: Accommodation, universal design, and access to participation in research. Archives of Physical Medicine and Rehabilitation, 81(2) S5-S9. doi:10.1053/apmr.2000.20618. 
National Center for Education Statistics, U.S. Department of Education. (2012). Digest of education statistics, 2011. Retrieved March 27, 2014, from National Center for Education Statistics Web site: nces.ed.gov/pubs2012/2012001.pdf

Olney, M. F., \& Brockelman, K. F. (2005). The impact of visibility of disability and gender on the self-concept of university students with disabilities. Journal of Postsecondary Education and Disability, $18(1), 80-91$.

Peña, E. V. (2014). Marginalization of Published Scholarship on Students with Disabilities in Higher Education Journals. Journal of College Student Development, 55(1), 30-40.

Porter, S. R. (2011). Do College Student Surveys Have Any Validity? The Review of Higher Education, 35(1), 45-76. doi:10.1353/rhe.2011.0034 Porter, S. R. (2013). Self-Reported Learning Gains: A Theory and Test of College Student Survey Response. Research in Higher Education, 54(2), 201-226. doi:10.1007/s11162-012-9277-0

Powers, L. E., Sowers, J., \& Stevens, T. (1995). An exploratory randomized study of the impact of mentoring on the self-efficacy and community-based knowledge of adolescents with severe physical challenges. Journal of Rehabilitation, 61(1), 33-41.

Rios-Aguilar, C. (2014). The changing context of critical quantitative inquiry. In F. K. Stage \& R. S. Wells (Eds.), New Scholarship in Critical Quantitative Research - New Directions for Institutional Research: No.158 (pp. 95-107). San Francisco, CA: Jossey-Bass. Shakespeare, T. (2006). The social model of disability. The disability studies reader, 2, 197-204.

Smart, J. C. (2005). Attributes of exemplary research manuscripts employing quantitative analyses. Research in Higher Education, $46(4), 461-477$. doi:10.1007/s11162-005-2970-5 
Stage, F. K. (2007). Using quantitative data to answer critical questions. New Directions for Institutional Research: No. 133. San Francisco: Jossey Bass.

Stage, F. K., \& Milne, N. V. (1996). Invisible Scholars: Students with Learning Disabilities. The Journal of Higher Education, 67(4), 426445. doi:10.2307/2943806

Stage, F. K., \& Wells, R. S. (2014). Critical quantitative inquiry in context. In F. K. Stage \& R. S. Wells (Eds.), New Scholarship in Critical Quantitative Research - New Directions for Institutional Research: No.158 (pp.1-7). San Francisco, CA: Jossey-Bass. Troiano, P. F. (2003). College Students and Learning Disability: Elements of Self-Style. Journal of College Student Development, $44(3), 404-419$. doi:10.1353/csd.2003.0033

United States Government Accountability Office. (2009). Higher education and disability: Education needs a coordinated approach to improve its assistance to schools in supporting students. Retrieved March 27, 2014, from U.S. Government Accountability Office Web site: http://www.gao.gov/assets/300/297433.pdf

Watson, N., Roulstone, A. \& Thomas, C. (Eds.). (2014). The Routledge Handbook of Disability Studies. New York: Taylor Francis. Weber, M. C. (2001). Disability Discrimination in Higher Education. Journal of College and University Law, 28, 439.

Wei, X., Yu, J., Shattuck, P., McCracken, M., \& Blackorby, J. (2013). Science, technology, engineering, and mathematics (STEM) participation among college students with an autism spectrum disorder. Journal of Autism and Developmental Disorders, 43(7), 1539-1546. doi:10.1007/s10803-012-1700-z

Wells, R., Lynch, C., \& Seifert, T. (2011). Methodological options and their implications: an example using secondary data to analyze 
Latino educational expectations. Research in Higher Education, $52(7), 693-716$. doi:10.1007/s11162-011-9216-5

West, M., Kregel, J., Getzel, E. E., Zhu, M., \& al, et. (1993). Beyond section 504: Satisfaction and empowerment of students with disabilities in higher education. Exceptional Children, 59(5), 456.

Williams, A. S., \& Moore, S. M. (2011). Universal design of research: inclusion of persons with disabilities in mainstream biomedical studies. Science Translational Medicine, 3(82), 1-5.

Ziliak, S. T., \& McCloskey, D. N. (2008). The cult of statistical significance: how the standard error costs us jobs, justice, and Iives. Ann Arbor, MI: University of Michigan Press. 